\title{
Composition chimique des fèces de bovins, d'ovins et de caprins exploitant des parcours naturels ou agro-pastoraux sahélo-soudaniens : utilisation pour estimer la valeur nutritive de leur régime
}

\author{
H Guerin1, D Richard², A Duché1, P Lefèvre1 \\ ${ }^{1}$ IEMVT/CIRAD, 10, rue Pierre-Curie, 94704 Maisons-Alfort, Cedex France; \\ 2 LNERVIISRA, BP 2057, Dakar, Sénégal
}

\begin{abstract}
Summary - The chemical composition of grazing cattle, sheep and goat feces is described according to animal species, type of range (natural pasture or fields after crops) and season in a subSahelian environment. Nutritive value (organic matter digestibility and digestible crude protein) of forages can be estimated from some chemical fecal criteria.
\end{abstract}

Introduction - Nous avons étudié les variations de la composition des fèces de bovins $(B)$, d'ovins $(O)$ et de caprins $(C)$ exploitant des parcours sénégalais et en avons déduit celles de la valeur nutritive de leur régime (Chenost, 1985).

Matériel et Méthodes - Les prélèvements de fèces ont été effectués à des intervalles de 4 à 6 semaines sur des parcours naturels $(20$ échantillons par espèce) ou des terroirs agropastoraux ( 30 échantillons par espèce) décrits par ailleurs (Guerin et al, 1989a). Chaque échantillon correspond au mélange de l'excrétion fécale totale pendant $5 \mathrm{j}$ consécutifs de 5 à 8 zébus, béliers ou boucs en croissance. On a dosé les teneurs en cendres (CE), cellulose brute (CB), lignocellulose (ADF) et matières azotées résiduelles de l'ADF (MAADF) sur les échantillons séchés pendant $24 \mathrm{~h}$ à $80^{\circ} \mathrm{C}$.

La digestibilité de la matière organique (DMO) et la teneur en matières azotées digestibles (MAD) des fourrages consommés ont été estimées à l'aide d'équations déduites de 63 essais de digestibilité sur moutons ne faisant appel qu'à des critères chimiques fécaux ( $f$ ) (Guerin et al, 1989b) : DMO $=0,63 \mathrm{MAT} f+$ $0,53 \mathrm{CB} f-0,77$ (ADF - MAADF) $f+61.8 \pm 4.8$, $R=0.75 ; \mathrm{MAD}=0,26 \mathrm{CB} f+0,91$ (MAT MAADF) $f-13 \pm 2.8, \quad R=0.83$; avec DMO en $\%$ et MAT, CB, ADF, MAADF en $\%$ de MO.

Résultats et Discussion - Les teneurs des fèces en CE (tableau I) sont plus éle- vées en saison des pluies (SP) qu'en saison sèche (SS) et pour les $B$ ou les $O$ que pour les $\mathrm{C}$. Elles varient en fonction de la digestibilité des fourrages et de leur contamination par de la terre. Les teneurs en $C B$ et en ADF augmentent quand la digestibilité des parois diminue; les teneurs en ADF, plus élevées pour les petits ruminants que pour les bovins, varient aussi en fonction de la composition botanique des régimes. Les teneurs en MAT diminuent au cours de la SP mais peuvent augmenter en SS lorsque les animaux ingèrent des fourrages de bonne valeur nutritive (fanes d'arachide) ou riches en azote peu digestible (fourrages ligneux); elles sont plus faibles pour les $B$ que pour les petits ruminants. Les teneurs en MAADF ont les mêmes sources de variation et augmentent surtout avec le pourcentage de fourrages ligneux dans le régime; elles constituent respectivement 27 à 57,33 à 63 et 42 à $70 \%$ des MAT des fèces des $B$, des $O$ et des $C$.

La DMO estimée des fourrages consommés (fig 1) varie de 66 à $47 \%$. Les teneurs en MAD atteignent $12 \%$ de la $M O$ en SP. On observe en SP une diminution rapide de la qualité des régimes avec, en milieu agro-pastoral, une amélioration en début de SS, lorsque les animaux ont 
Tableau I. Composition chimique des fèces de bovins, d'ovins et de caprins exploitant des parcours naturels ou agro-pastoraux sahélo-soudaniens en saison des pluies (SP) et en saison sèche (SS).

\begin{tabular}{llllll}
\hline Valeurs extrêmes & $\begin{array}{l}\text { Cendres } \\
(\% M S)\end{array}$ & $C B$ & $A D F \quad$ MAT & MAADF \\
& & & & & \\
\hline $\begin{array}{l}\text { Milieu pastoral } \\
\text { bovins } \\
\quad \text { ovins }\end{array}$ & $13-14$ & $31-61$ & $47-65$ & $11-23$ & $5-8$ \\
$\begin{array}{l}\text { Milieu agro-pastoral } \\
\text { bovins }\end{array}$ & $14-33$ & $30-44$ & $50-66$ & $14-23$ & $6-13$ \\
$\quad \begin{array}{l}\text { ovins } \\
\text { caprins }\end{array}$ & $23-41$ & $28-37$ & $45-55$ & $11-20$ & $5-9$ \\
\hline
\end{tabular}

accès aux résidus de récolte. Les résultats relatifs aux $\mathrm{C}$ ne concernent que le système agro-pastoral : les variations saisonnières de leur régime sont moins dépendantes de la pluviosité que pour les $\mathrm{O}$ ou les $B$, ce qui confirme leur comportement alimentaire plus sélectif.

Conclusion - Les variations de la composition des fèces sont fonction des ressources fourragères de l'année, de la sajson et de l'espèce animale. L'application à des $\mathrm{C}$ ou à des $\mathrm{B}$ de relations mises au point avec des $\mathrm{O}$ est critiquable. Elle permet cependant d'étudier les variations de la valeur des régimes.

Chenost M (1985) Ann Zootech 34, 205-228

Guerin $H$, Richard D, Friot $O$, Mbaye N, Sall C (1989a) XV/e International Grassland Congress, Nice, 4-11 Oct 1989, vol 2, 10811082

Guerin $H$, Richard D, Lefèvre P, Friot D, Mbaye $N$ (1989b) XV|⿱日一 International Grassland Congress, Nice, 4-11 Oct 1989 vol 2, 879880
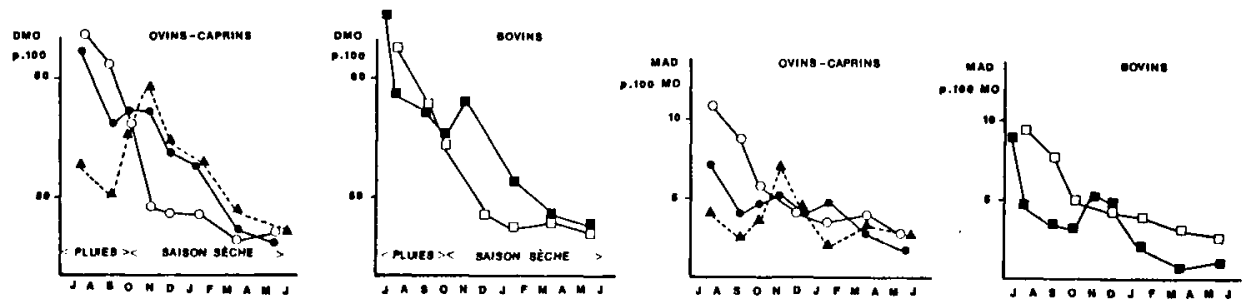

Fig 1. Digestibilité de la matière organique (DMO en \%) et teneurs en matières azotées digestibles (MAD \% MO) du régime des $\mathrm{O}(\mathrm{O}, \boldsymbol{\theta})$, des $\mathrm{C}(\boldsymbol{\Delta})$ et des $\mathrm{B}(\square, \mathrm{a})$ exploitant des parcours naturels $(\mathrm{O}$,

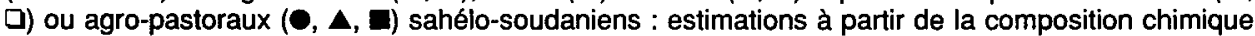
des fèces. 